\title{
Calcium and phosphorus balance in extremely low birthweight infants in the first six weeks of life
}

\author{
A J LYON AND N McINTOSH \\ Department of Child Health, St George's Hospital Medical School, London
}

SUMMARY The absorption and retention of calcium and phosphorus in infants of 28 weeks' gestation, or less, who were fed either breast milk or a preterm formula, were determined in 22 balance studies. Breast milk contained significantly lower amounts of calcium and phosphorus than the formula milk. The percentage absorption of calcium was similar in the two groups, but the infants fed breast milk had greater urinary calcium losses and significantly lower calcium retention than the group fed formula milk. The percentage phosphate absorption was also similar in the two groups but because of the higher phosphate intake in the formula milk this group retained a significantly greater amount of phosphate. The extremely low birthweight infants fed on breast milk were phosphorus depleted, with low plasma phosphate concentrations, and seemed to retain as much phosphate as possible. The hypophosphataemia may result in reduced deposition of calcium in bone and explain the calciuria in the breast fed infants. Substrate deficiency may be an important factor in the aetiology of rickets of prematurity and, particularly if breast milk is used, preterm infants may require calcium and phosphate supplements from an early age.

Bone mineralisation is commonly inadequate in the extremely low birthweight infant after birth. The incidence of radiological rickets is high, ${ }^{1}$ and this can lead to increased morbidity from fractures ${ }^{2}$ and late onset respiratory distress. ${ }^{3}$ The concentrations of the vitamin $\mathrm{D}$ metabolites in these infants have been reported as normal or high, and rickets has occurred despite high vitamin $\mathrm{D}$ intakes. ${ }^{45}$

There is increasing evidence that at a time of rapid postnatal growth the deficiency of dietary calcium and phosphorus is a major factor in the aetiology of rickets. ${ }^{6} 7$ Expressed breast milk, with its relatively low calcium and phosphorus content, may not be the ideal milk for these very immature infants.

The purpose of this study was to measure the absorption and retention of calcium and phosphorus in infants of 28 weeks' gestation, or less, who were fed with either breast milk or a preterm formula and who were on a daily vitamin D intake of $2000 \mathrm{U}$.

\section{Patients and methods}

Thirteen consecutive preterm infants were studied, their details are shown in Table 1. Gestational age was confirmed from ultrasound scan early in pregnancy and by Dubowitz assessment after delivery.
Table 1 Details of infants

\begin{tabular}{lllll}
\hline Sex & $\begin{array}{l}\text { Gestation } \\
\text { (weeks) }\end{array}$ & $\begin{array}{l}\text { Birthweight } \\
(g)\end{array}$ & $\begin{array}{l}\text { Age at study } \\
\text { (days) }\end{array}$ & Milk* $^{*}$ \\
\hline F & 28 & 1170 & 21,36 & F/F \\
F & 26 & 860 & 21 & E \\
F & 28 & 900 & 11 & E \\
M & 26 & 940 & $19,33,47$ & F/F/F \\
F & 25 & 730 & 35 & E \\
F & 28 & 960 & 5 & E \\
M & 28 & 960 & 35 & E \\
M & 27 & 1190 & 15 & E \\
F & 28 & 1190 & 15 & F/F/F \\
F & 25 & 950 & $22,35,50$ & E/F \\
M & 27 & 890 & 6,37 & F/F \\
M & 28 & 900 & $11,19,26$ & F/E/E \\
M & 27 & 900 & & \\
\hline
\end{tabular}

*F=SMA low birthweight formula; $E=$ expressed breast milk.

Twenty two balance studies, each lasting three days, were performed, starting when the infant was clinically well and on full oral feeds. Pooled, pasteurised breast milk or 'ready to feed' SMA low birthweight formula (Wyeth Laboratories) was used, the infants being adapted to the milk for at least seven days before each balance study. The composition of these milks is shown in Table 2 . During the balance study periods, each infant received $0.6 \mathrm{ml}$ Abidec (Parke Davis) and $1600 \mathrm{U}$ of 
Table 2 Composition of milk (values mean (SD))

\begin{tabular}{llll}
\hline & $\begin{array}{l}\text { Calcium } \\
(\text { mmoll100 ml })\end{array}$ & $\begin{array}{l}\text { Phosphorus } \\
(\text { mmol/100 ml })\end{array}$ & Fat $(\mathrm{g} / 100 \mathrm{ml})$ \\
\hline $\begin{array}{l}\text { Expressed breast } \\
\text { milk }\end{array}$ & $0.70(0.09)$ & $0.42(0.26)$ & $4.26(0.99)$ \\
$\begin{array}{l}\text { SMA low } \\
\text { birthweight } \\
\text { formula }\end{array}$ & $\begin{array}{l}1.90(0.05) \\
\mathrm{P}<0.001\end{array}$ & $\begin{array}{l}1.29(0.07) \\
\mathrm{P}<0.001\end{array}$ & $\begin{array}{l}4.37(0.41) \\
\mathrm{NS}\end{array}$ \\
\hline
\end{tabular}

Conversion-SI to traditional units: phosphorus $1 \mathrm{mmol} / 100 \mathrm{ml} \approx 3.1 \mathrm{mg} / 100 \mathrm{ml}$; calcium $1 \mathrm{mmol} / 100 \mathrm{ml} \approx 4 \mathrm{mg} / 100 \mathrm{ml}$

calciferol daily (total vitamin D intake of 2000 U/day).

The feeds for the three day period were prepared on the first day and an aliquot taken for analysis. Each feed was preweighed and given by nasogastric tube or bottle, the container being weighed again after the feed. Any spillage or vomit was collected onto weighed ashless filter papers and stored frozen. This was subtracted from the intake. Analysis of calcium and phosphorus showed these to be similar to that of the milk. Fat in the vomit was not analysed and it was assumed that this was regurgitated in proportion.

Two carmine markers, given exactly three days apart, were used to time the stool collection. Faeces were collected onto weighed ashless filter papers held in place by a plastic nappy. At each change, the infant's bottom was cleaned with filter paper dampened with deionised water. All stool plus filter paper were frozen for later analysis. No ointments or creams were used on the infant's bottom during the balance period.

One of the major problems in balance studies, particularly in girls, is the collection of urine separately from stools. The method used in this study was a modification of that described by Liu and Anderson ${ }^{9}$ and it achieved a high measure of success in both girls and boys. The urine bag was made from the finger of a disposable plastic glove, the cut top being heat sealed. A small hole at a top corner allowed two 6 FG tubes to be placed in the bag, the hole then being sealed by tape. Air was pumped continually into the bag through one tube and aspirated continuously, with any urine passed, through the other, into a container surrounded by ice. The air blown into the bag prevented a vacuum being created and the bag collapsing. A hole cut in one side of the bag allowed it to be attached to the baby. In boys, the penis was pushed through the hole and the bag sealed to the baby using silastic spray adhesive (Dow Corning). In girls, the bag was attached round the vulva and perineum by a ring of Stomahesive (Squibb Surgicare), similar to the application of an ileostomy bag. Leakage problems were minimal although in girls the bag often needed to be changed at least once during the balance period.

All glassware used for collection of specimens or during later analysis was washed for 24 hours in $10 \%$ nitric acid.

The milk samples, homogenised stools, and filter papers were all freeze dried. The fat content of aliquots was esimated using a gravimetric method after releasing the triglycerides by boiling with $50 \%$ hydrochloric acid and extracting them with petroleum ether in Soxhlets apparatus.

The remaining freeze dried milk and stool with filter paper were ashed at $550^{\circ} \mathrm{C}$ for 12 to 14 hours, the ash was dissolved in $50 \%$ nitric acid and the solution diluted to $500 \mathrm{ml}$ with deionised water. Calcium in urine, milk, and stool was determined by atomic absorption spectrophotometry. Phosphate was estimated by a colorimetric method, ${ }^{10}$ based on the method of Goldenberg and Fernandez. ${ }^{11}$ Plasma calcium, phosphate, and alkaline phosphatase were measured, by standard laboratory autoanalyser methods, during each balance period.

Wrist radiographs had been performed in 11 of the infants from 28 days of age and these were reviewed for any changes of radiological rickets. ${ }^{1}$

\section{Results}

The results of the first balance study on each infant are summarised in Table 3 as mean (SD) and the

Table 3 Summary of results from first balance study in each infant (values mean (SD))

\begin{tabular}{|c|c|c|c|}
\hline & $\begin{array}{l}\text { Preterm } \\
\text { formula } \\
(n=5)\end{array}$ & $\begin{array}{l}\text { Expressed } \\
\text { breast milk } \\
(n=8)\end{array}$ & $P$ \\
\hline Intake $(\mathrm{ml} / \mathrm{kg} /$ day & $180(25 \cdot 25)$ & $202 \cdot 28(23 \cdot 12)$ & NS \\
\hline \multicolumn{4}{|c|}{ Calcium (mmol/kg/day) } \\
\hline Intake & $3.20(0.41)$ & $1.57(0.28)$ & $<0.001$ \\
\hline Stools & $1.86(0.49)$ & $1.04(0.35)$ & $<0.01$ \\
\hline Urine & $0.03(0.02)$ & $0.08(0.04)$ & $<0.05$ \\
\hline$\%$ absorption & $42 \cdot 1(13 \cdot 2)$ & $34 \cdot 1(17 \cdot 6)$ & NS \\
\hline Retention & $1.32(0.46)$ & $0.46(0.21)$ & $<0.01$ \\
\hline$\%$ retention & $41 \cdot 5(12 \cdot 6)$ & $29.4(15.6)$ & $<0.05$ \\
\hline \multicolumn{4}{|c|}{ Phosphate (mmol/kg/day) } \\
\hline Intake & $2 \cdot 18(0 \cdot 32)$ & $1.01(0.51)$ & $<0.001$ \\
\hline Stools & $0.34(0.24)$ & $0.13(0.05)$ & $<0.005$ \\
\hline Urine & $0.30(0 \cdot 16)$ & $0.03(0.02)$ & $<0.001$ \\
\hline$\%$ absorption & $82 \cdot 5(15 \cdot 1)$ & $86 \cdot 1(7 \cdot 5)$ & NS \\
\hline Retention & $1.51(0.46)$ & $0.86(0.50)$ & $<0.01$ \\
\hline$\%$ retention & $69 \cdot 2(13 \cdot 8)$ & $84.3(10 \cdot 1)$ & $<0.001$ \\
\hline \multicolumn{4}{|l|}{ Fat (g/kg/day) } \\
\hline Intake & $7 \cdot 6(1 \cdot 1)$ & $8.7(2.4)$ & NS \\
\hline Stools & $2.6(0.6)$ & $2.3(0.7)$ & NS \\
\hline$\%$ absorption & $65 \cdot 7(7 \cdot 5)$ & $72 \cdot 6(8 \cdot 8)$ & NS \\
\hline
\end{tabular}

Conversion-SI to traditional units: phosphate $1 \mathrm{mmo} / \mathrm{kg} /$ day $\approx 30.9$ $\mathrm{mg} / \mathrm{kg} /$ day; calcium $1 \mathrm{mmol} / \mathrm{kg} /$ day $\approx 40 \mathrm{mg} / \mathrm{kg} /$ day. 
two groups compared by a non paired two tailed Student's $t$ test.

Calcium. Infants fed preterm formula had a higher intake and net absorption of calcium than those fed expressed breast milk. Although the mean percentage absorption was greater in the formula fed infants, the scatter was such that the differences between the two groups was not significant. This suggests that the increased absorption of calcium in the infants fed preterm formula was due to their higher intake. The net retention of calcium, and the retention expressed as a percentage of intake was, however, significantly higher in the infants fed preterm formula. In the infants fed expressed breast milk, $15 \%$ of the calcium absorbed from the gut was found in the urine compared with only $2 \%$ of the absorbed calcium in the preterm formula group, $(\mathrm{P}<0 \cdot 01)$.

Phosphate. The infants fed on preterm formula had a higher intake and significantly higher net absorption of phosphate compared with those fed on expressed breast milk. As with calcium, the higher absorption was due to the increased intake, as percentage absorption was the same in the two groups. The retention of phosphate expressed as a percentage of intake was higher in the infants fed expressed breast milk, but because of the higher intake the preterm formula group had a higher net retention of phosphate. Twenty six per cent of the phosphate absorbed by the infants fed preterm formula was found in the urine compared with only $2 \%$ in the expressed breast milk group $(\mathrm{P}<0 \cdot 01)$.

Changes with postnatal age. The following changes were noted with increasing postnatal age.

\section{Calcium}

The retention of calcium, expressed as a percentage of intake, showed a steady rise with postnatal age, the increase being significantly greater $(\mathrm{P}<0.01)$ for the preterm formula group compared with the group fed expressed breast milk (Fig. 1). Urinary losses of calcium did not change with postnatal age, remaining at 2 to $3 \%$ of the absorbed calcium in the preterm formula infants compared with 12 to $17 \%$ in the expressed breast milk group.

Table 4 shows the mean plasma calcium and phosphate concentrations calculated from the data of the individual infants studied at various times. Plasma calcium values did not change significantly with postnatal age. The infants fed expressed breast milk, despite their lower net retention of calcium, were able to maintain their plasma calcium concen-

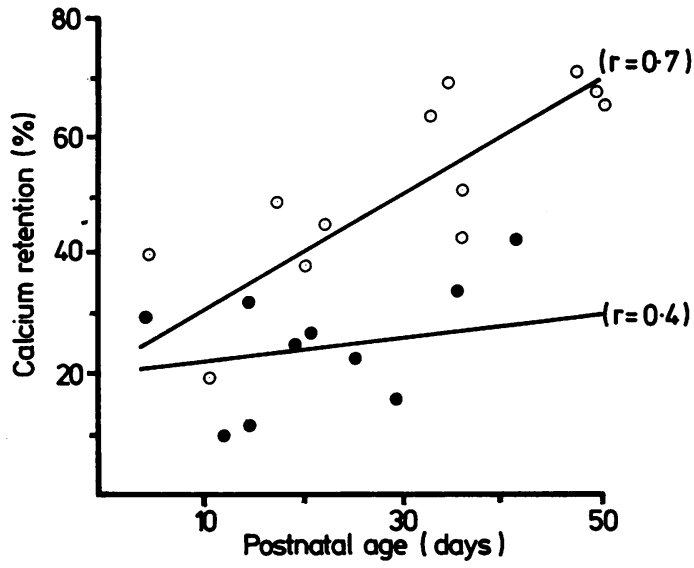

Fig. 1 Changes in percentage calcium retention with postnatal age in infants of 28 weeks' gestation, or less, fed on expressed breast milk (O) or a preterm formula milk (O).

trations at values similar to those found in the preterm formula group.

\section{Phosphate}

The absorption and retention of phosphate were high early in postnatal life and did not change with age, (Fig. 2, c and d). The plasma phosphate concentration was always significantly lower in the infants fed expressed breast milk, although in this group there was a steady rise in plasma phosphate values with postnatal age (Table 4).

\section{Alkaline phosphatase}

The infants fed expressed breast milk had significantly higher alkaline phosphatase activities (mean (SD) $604.6(216.3) \mathrm{U} / \mathrm{l}$ than those fed preterm formula (mean (SD) $357.2(98 \cdot 1) \mathrm{U} / \mathrm{l} ; \mathrm{P}<0.05)$. In the breast fed infants the alkaline phosphatase activity increased with postnatal age, but there was no change in the values found in infants fed preterm formula (Fig. 3).

Table 4 Mean plasma calcium and phosphate concentrations with postnatal age

\begin{tabular}{|c|c|c|c|c|c|c|}
\hline & \multicolumn{6}{|c|}{ Postnatal age (weeks) } \\
\hline & 1 & 2 & 3 & 4 & 5 & 6 \\
\hline \multicolumn{7}{|l|}{ Calcium (mmolll) } \\
\hline Preterm formula & $2 \cdot 12$ & $2 \cdot 34$ & $2 \cdot 29$ & $2 \cdot 06$ & $2 \cdot 26$ & $2 \cdot 04$ \\
\hline Expressed breast milk & $2 \cdot 20$ & $2 \cdot 27$ & $2 \cdot 30$ & $2 \cdot 20$ & $2 \cdot 17$ & $2 \cdot 17$ \\
\hline \multicolumn{7}{|l|}{ Phosphate (mmol/l) } \\
\hline Preterm formula & $1 \cdot 58$ & $2 \cdot 28$ & $1 \cdot 78$ & 1.79 & $2 \cdot 15$ & 1.98 \\
\hline Expressed breast milk & $0 \cdot 80$ & 0.87 & $1 \cdot 08$ & 1.48 & 1.67 & 1.75 \\
\hline
\end{tabular}
calcium $1 \mathrm{mmol} / \mathrm{l} \approx 4 \mathrm{mg} / \mathrm{I}(x) \mathrm{ml}$ 

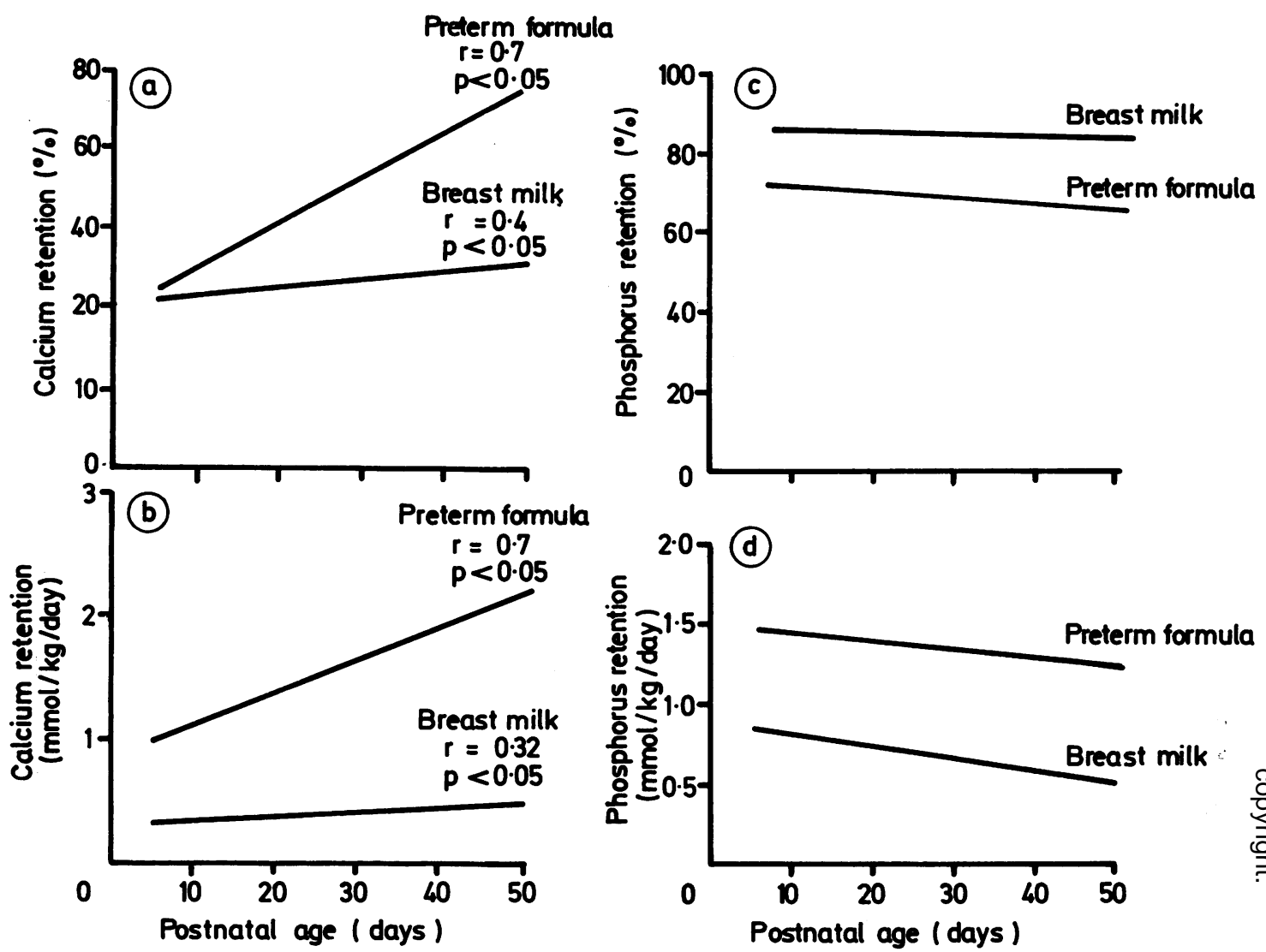

Fig. 2 Changes in (a) percentage calcium retention (of intake), (b) net calcium retention, (c) percentage phosphorus retention (of intake), and (d) net phosphorus retention with postnatal age in infants of 28 weeks' gestation, or less, fed expressed breast milk or a preterm formula milk.

Conversion-SI to traditional units: phosphorus $1 \mathrm{mmol} / \mathrm{kg} /$ day $\approx 30.9 \mathrm{mg} / \mathrm{kg} / \mathrm{day} ;$ calcium $1 \mathrm{mmol} / \mathrm{kg} / \mathrm{day} \approx 40 \mathrm{mg} / \mathrm{kg} / \mathrm{day}$.

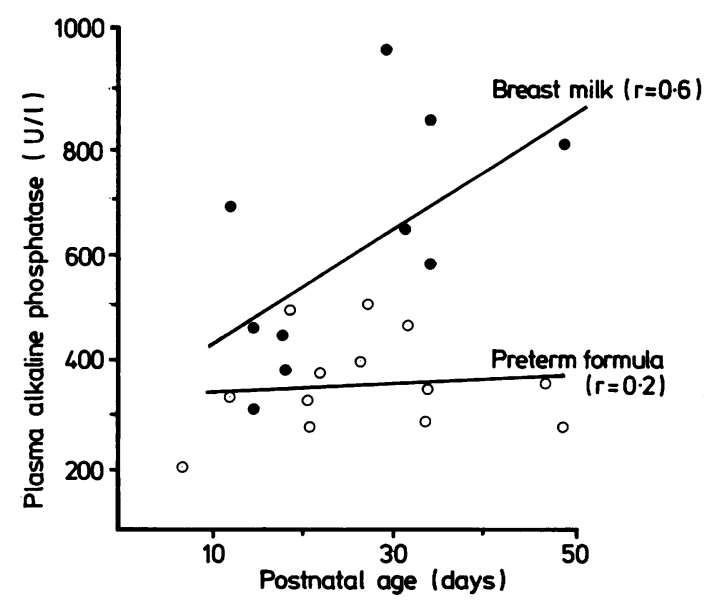

Fig. 3 Changes in plasma alkaline phosphatase values with $\stackrel{0}{\circ}$ postnatal age in infants $\leqslant 28$ weeks' gestation fed expressed breast milk (O) or a preterm formula milk (O).

Radiographs

The two infants who did not have adequate radiographs taken were both fed expressed breast milk. Three of the remaining five infants in this group had $N$ radiological evidence of rickets. Five of the six infants fed preterm formula developed rickets. All $\tilde{O}$ infants had developed radiological rickets by $6 \underset{\omega}{N}$ weeks of age.

\section{Discussion}

The infants fed on formula milk had a significantly 
greater intake and retention of calcium and phosphorus compared with those fed breast milk. Whereas the retention of calcium expressed as a percentage of the intake was significantly higher in the former group, the percentage of the phosphate retained was significantly less than in the infants fed expressed breast milk. When fed on breast milk, the very low birthweight infant seems to be retaining as much phosphate as possible; this suggests an attempt to maintain adequate plasma phosphate concentrations which are significantly lower than in the group fed formula.

In the presence of hypophosphataemia, calcium will not be utilised by bone and will be excreted in the urine. This may explain why, despite a much lower calcium retention, the infants fed expressed breast milk had significantly greater urinary calcium concentrations than those fed on preterm formula. A reduction in urinary calcium loss and the subsequent improvement in calcium retention after an increase in dietary phosphate has been reported. ${ }^{13}$ In the extremely low birthweight infant there is evidence that hypophosphataemia may lead to not just a failure of mineralisation but also to an active demineralisation of bone, as the infants attempt to maintain their plasma phosphate concentration for its essential role in soft tissue maintenance and growth. The bone demineralisation has resulted in serious hypercalcaemia in several cases which responded dramatically to an increased phosphate intake. ${ }^{14}$

A similar phosphorus depletion syndrome has been described in adults. ${ }^{15}$ The possible role of phosphorus deficiency in causing problems in ossification in preterm infants is supported by histopathological studies of bone in neonatal rickets which showed changes similar to those reported in experimental phosphate deficient rickets. ${ }^{16}$

The infants in this study had a lower retention of calcium than reported in other studies which included more mature infants. ${ }^{17} 18$ The differences were due to a lower absorption of calcium from the gut and possibly reflect the immaturity of these infants. With increasing postnatal age the absorption of calcium increased, and in formula fed infants this resulted in a steady rise in calcium retention. In infants fed expressed breast milk, calcium retention increased only slightly with postnatal age, urinary calcium losses remaining high. This failure to improve calcium retention despite increasing maturity may be related in some way to the continued low phosphate intake in these infants.

Breast milk has advantages for the preterm infant particularly with its anti-infective properties. It has, however, been designed for the term infant whose relative growth rate is much slower than that of most mammals. The problem with inadequate mineral content of human milk was highlighted by studies as early as $1946 .{ }^{19}$ More recently, the use of photon absorptiometry to determine bone mineral content, has shown a lower rate of mineralisation in breast fed infants compared with those given a formula milk. ${ }^{20}$ The intrauterine accumulation of calcium and phosphorus at 28 weeks' gestation has been estimated at 3.2 and $2.5 \mathrm{mmol} / \mathrm{kg} /$ day respectively, ${ }^{21}$ very much higher than the retention of calcium and phosphate in both of the groups of infants studied. After the initial few days of weight loss, however, these preterm infants had a mean weight gain of 15 $\mathrm{g} / \mathrm{kg} /$ day, a rate similar to that achieved in utero. ${ }^{22}$

In this study, there was no difference in the incidence or severity of radiological rickets in the two groups, although the alkaline phosphatase values were higher and increased more rapidly with postnatal age in the infants fed expressed breast milk compared with those on formula milk. It is of interest that the formula fed infants had definite changes of radiological rickets despite normal alkaline phosphatase activities which is unusual as biochemical changes usually precede the abnormal radiological findings.

The finding of radiological rickets in these infants suggests that even a preterm formula like SMA may contain insufficient calcium and phosphate. Infants fed this formula still had mineral retentions which were only about $50 \%$ of the intrauterine accumulation. It has been the policy of the unit that all preterm infants be fed initially with breast milk, supplemented where necessary by parenteral nutrition. This initial period of very low mineral intake could have caused rachitic changes which even the higher calcium and phosphorus intakes from formula feeds would take time to reverse. In all cases the rickets healed spontaneously with no serious clinical problem.

Extremely low birthweight infants fed expressed breast milk or preterm formula have low calcium and phosphorus accumulations in the first six weeks of life and this may be a major aetiological factor in rickets of prematurity. As similar growth rates to those of the fetus are being achieved, it may be more logical to aim for mineral intakes nearer to the accumulation rate in utero.

We thank the nursing and medical staff on the Neonatal Unit for their care and cooperation in managing these small infants and Mrs S Garrett, and Mrs V Williams for their secretarial help. We thank Wyeth for their gift of the preterm formula milk.

\section{References}

1 Kulkarni PB, Hall RT, Rhodes PG, et al. Rickets in very low birthweight infants. $J$ Pediatr 1980;96:249-52. 
2 Geggel RL, Pereira GP, Spackman TJ. Fractured ribs: unusual presentation of rickets in premature infants. $J$ Pediatr 1978;93:680-2.

${ }^{3}$ Glasgow JFT, Thomas PS. Rachitic respiratory distress in small premature infants. Arch Dis Child 1977;52:268-74

${ }^{4}$ McIntosh N, Livesey A, Brooke OG. Plasma 25 hydroxy vitamin $\mathrm{D}$ and rickets in infants of extremely low birthweight. Arch Dis Child 1982;57:848-50.

${ }^{5}$ Steichen JJ, Tsang RC. Greer FR, Ho M, Hug G. Elevated serum 1,25 dihydroxyvitamin $D$ concentrations in rickets of very low birthweight infants. J Pediatr 1981;99:293-8.

${ }^{6}$ Steichen JJ, Grattan TL, Tsang RC. Osteopenia of prematurity: the cause and possible treatment. J Pediatr 1980;96:528-34.

${ }^{7}$ Lapatsanis P, Daffron-Ierodiakonou E, Makaronis G, Doxiadis S. Phosphate deficiency and rickets. Arch Dis Child 1981;56:653.

${ }^{8}$ Dubowitz, LMS, Dubowitz V, Goldberg C. Clinical assessment of gestational age in the newborn infant. J Pediatr 1970;77:1-10.

9 Liu HY, Anderson GJ. A method for long term quantitative and fractional urine collection. $J$ Pediatr 1967:70:276-9.

11) Weissman N, Pileggi VJ. Inorganic anions. In: Henry RJ, Cannon DC, Winkelman JW, eds. Clinical chemistry: principles and technics. 2nd ed. New York: Harper and Row, 1974:723-7.

1 Goldenberg H, Fernandez A. Simplified method for the estimation of inorganic phosphorus in body fluids. Clin Chem 1966;12:871-82.

12 Koo WWK, Gupta JM, Nayanar VV, Wilkinson M, Posen S. Skeletal changes in preterm infants. Arch Dis Child 1982;57:447-52.

${ }^{13}$ Senterre J, Putet G, Salle B, Rigo J. Effects of vitamin D and phosphorus supplementation on calcium retention in preterm infants fed banked human milk. J Pediatr 1983;103:305-7.
14 Lyon AJ, McIntosh N, Wheeler K, Brooke OG. Hypercal- $\frac{\Omega}{\partial}$. caemia in extremely low birthweight infants. Arch Dis Child $\overline{\overline{2}}$

1584:59:1141-4.
Lotz M, Zisman E, Bartter F. Evidence for a phosphorus $\overrightarrow{\overline{\vec{A}}}$ depletion syndrome in man. $N$ Engl $J$ Med 1968;278:409-15.

16 Oppenheimer SJ, Snodgrass GJAI. Neonatal rickets; histopathological and quantitative bone changes. Arch Dis Child 흐 1980;55:945-9.

17 Shaw JCL. Evidence for defective skeletal mineralization in low birthweight infants: the absorption of calcium and fat. Pediatrics 0 1976;57:16-26.

18 Rowe J, Rowe D, Horak E, et al. Hypophosphataemia and hypercalciuria in small premature infants fed human milk;. evidence for inadequate dietary phosphate. $J$ Pediatr 1984;104:112-7.

19 von Sydow G. A study of the development of rickets in

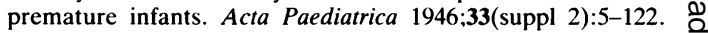

20) Chesney RW, Shore RM. Non invasive determination of bone? mineral content by photon absorptiometry. Am J Dis Child $\mathrm{G}$ 1982;136:578-680.

21 Widdowson EM, Dauncey JD, Shaw JCL. Trace elements in $\vec{N}$ fetal and early postnatal development. Proc Nutr Soc $\overrightarrow{\vec{H}}$ 1974:33:275-84.

22 Lubchenko LO, Hansman C, Dressler M, et al. Intrauterine cै growth as estimated from live born data at 24 to 42 weeks of $ᄋ$ gestation. Pediatrics 1963;32:793-800.

Correspondence to Dr N McIntosh, Department of Child Health, St George's Hospital Medical School, London SW17.

Received 28 June 1984 